G. Florholmen - G. H. Thoresen - A. C. Rustan •

J. Jensen - G. Christensen - V. Aas

\title{
Leukaemia inhibitory factor stimulates glucose transport in isolated cardiomyocytes and induces insulin resistance after chronic exposure
}

Received: 11 July 2005 / Accepted: 9 November 2005 / Published online: 18 February 2006

C) Springer-Verlag 2006

\begin{abstract}
Aims/hypothesis: Hypertrophic and failing hearts have increased utilisation of glucose, but also develop insulin resistance and reduced ability to produce ATP. Increased levels of the IL-6-related cytokine leukaemia inhibitory factor (LIF) are found in failing hearts, and we have recently shown that LIF reduces ATP production in isolated cardiomyocytes. In the present study we investigated effects of LIF on glucose metabolism, and how LIF-treated cells respond to insulin stimulation. Methods: Cardiomyocytes were isolated from adult Wistar rats by collagen digestion, maintained in culture for $48 \mathrm{~h}$, and then treated with $1 \mathrm{nmol} / \mathrm{l} \mathrm{LIF}$. Results: Acute LIF treatment increased deoxyglucose uptake compared with controls, but no additive effect was observed in cardiomyocytes treated with LIF and insulin. The phosphatidylinositol 3-kinase inhibitor wort-
\end{abstract}

G. Florholmen $(\bowtie) \cdot$ G. Christensen

Institute for Experimental Medical Research,

Surgical building 4th floor,

Ullevaal University Hospital,

0407 Oslo, Norway

e-mail: geir.florholmen@medisin.uio.no

Tel.: +47-23-016800

Fax: +47-23-016799

G. Florholmen - G. Christensen

Center for Heart Failure Research,

University of Oslo,

Oslo, Norway

G. H. Thoresen - A. C. Rustan · V. Aas

Department of Pharmaceutical Biosciences,

School of Pharmacy,

University of Oslo,

Oslo, Norway

J. Jensen

National Institute of Occupational Health,

Oslo, Norway

V. Aas

Faculty of Health Sciences,

Oslo University College,

Oslo, Norway mannin did not affect LIF-induced glucose uptake. LIF had no effect on AMP-activated protein kinase phosphorylation. Cardiomyocytes treated with LIF for $48 \mathrm{~h}$ did not respond to insulin by increasing deoxyglucose uptake and showed a reduced insulin-mediated uptake of oleic acid and formation of complex lipids compared with control cells. Chronic LIF treatment increased gene expression of the suppressor of cytokine signalling (Socs) 3 and reduced expression of solute carrier family 2, member 4 (Slc2a4, previously known as glucose transporter 4 [Glut4]). In line with these observations, chronic LIF treatment reduced insulin-mediated phosphorylation of both Akt/protein kinase B (PKB) and glycogen synthase kinase (GSK)-3. Conclusions/interpretation: Acute LIF treatment increased glucose uptake in isolated cardiomyocytes by a pathway different from that of insulin. Chronic LIF treatment induced insulin resistance, possibly mediated by altered expression of Socs 3 and Slc2a4, and impaired insulin-mediated phosphorylation of GSK-3 and Akt/PKB.

Keywords Glucose uptake - Insulin resistance · Isolated cardiomyocytes - Leukaemia inhibitory factor

Abbreviations AMPK: AMP-activated protein kinase ARC: American Radiolabeled Chemicals - ASM: acid soluble metabolite $\cdot$ CD36: CD36 antigen - DAG: diacylglycerol - ERK: extracellular signal regulated kinase - GSK: glycogen synthase kinase - LIF: leukaemia inhibitory factor - MEK: mitogen-activated ERK-activating kinase - PI: phosphatidylinositol - PKB: protein kinase B . SLC2A1: solute carrier family 2 (facilitated glucose transporter), member 1. Previously known as glucose transporter 1 (GLUT1) - SLC2A4: solute carrier family 2 (facilitated glucose transporter), member 4. Previously known as glucose transporter 4 (GLUT4) - SOCS: suppressor of cytokine signalling - TAG: triacylglycerol

\section{Introduction}

Reduced ability to produce ATP is a hallmark change during development of heart failure [1]. One important change in 
energy metabolism is the increased reliance on glucose at the expense of fatty acids. As a result of reduced utilisation of fatty acids, the hypertrophic myocardium has increased consumption of glucose [2].

Increased levels of the IL-6-related cytokine leukaemia inhibitory factor (LIF) is observed in failing hearts, and it is believed that LIF participates in the progression to heart failure $[3,4]$. We recently showed that chronic LIF treatment reduced the ability to produce ATP and reduced cellular content of ATP in isolated cardiomyocytes [5]. We [5] and others [6] have found increased glucose uptake following LIF treatment for $48 \mathrm{~h}$. It is not known whether acute LIF treatment has similar effects on the uptake of glucose. Insulin increases glucose uptake in cardiomyocytes by translocating the solute carrier family 2, member 4 (SLC2A4, previously known as glucose transporter 4 [GLUT4]) to the plasma membrane by activation of the phosphatidylinositol (PI) 3kinase and Akt/protein kinase B (PKB) signalling pathway [7]. It has recently also been demonstrated that the $\mathrm{CAP} / \mathrm{Cbl}$ pathway contributes to insulin signalling in cardiomyocytes [8]. Insulin resistance is regarded as the inability to increase glucose uptake following insulin stimulation and is associated with changes in intracellular signalling and SLC2A4 translocation [9]. Glucose uptake is also increased by insulinindependent mechanisms such as activation of AMPactivated protein kinase (AMPK) [10].

Hypertrophic hearts develop insulin resistance and reduced SLC2A4 expression [11], and it has been suggested that impaired Akt/PKB signalling contributes to this development [12]. LIF has been shown to induce hypertrophy of cardiomyocytes in vitro $[13,14]$. The aim of this study was therefore to investigate effects of acute LIF treatment on glucose uptake, and to detect potential signalling pathways involved. In addition, we examined changes in glucose and fatty acid metabolism with a view to investigating whether chronic LIF treatment influenced the responsiveness of the cardiomyocytes to acute insulin stimulation.

\section{Materials and methods}

\section{Cardiomyocyte cultures}

Cardiomyocytes from male Wistar rats $(250-300 \mathrm{~g})$ (Møllegaard Breeding and Research Center and Bomholgård Breeding and Research Center, Ry, Denmark) were isolated by collagen digestion as described elsewhere [15]. The experiments were conducted in accordance with Regulations on Animal Experimentation under the Norwegian Animal Welfare Act and approved by the Norwegian Animal Research Authority. Isolated cells were maintained in Medium 199 (Sigma, St. Louis, MO, USA) with $2 \mathrm{mg} / \mathrm{ml}$ BSA, $2 \mathrm{mmol} / \mathrm{l} \mathrm{DL}$-carnitine, $5 \mathrm{mmol} / \mathrm{l}$ creatine, $5 \mathrm{mmol} / \mathrm{l}$ taurine, $0.1 \mu \mathrm{mol} / 1$ insulin, $0.1 \mathrm{nmol} / 1$ triiodothyronine (all from Sigma), $100 \mathrm{U} / \mathrm{ml}$ penicillin (Invitrogen, Paisley, UK) and $100 \mu \mathrm{g} / \mathrm{ml}$ streptomycin (Invitrogen) with or without $1 \mathrm{nmol} / \mathrm{l} \mathrm{LIF}$ (Chemicon, Temecula, CA, USA). This pro- cedure yields approximately $75 \%$ rod-shaped cardiomyocytes after $48 \mathrm{~h}$ in culture as previously reported [5]. It has previously been shown that adult cardiomyocytes maintained in culture in a serum-free medium remain insulin responsive [16].

\section{Glucose metabolism}

\section{Deoxyglucose transport}

Isolated cardiomyocytes were plated on six-well culture dishes (Corning Int., Corning, NY, USA), and measurements of $\left[{ }^{3} \mathrm{H}\right]$ deoxyglucose uptake were performed as described elsewhere [5]. In brief, the cells were maintained in culture for $48 \mathrm{~h}$ with or without $1 \mathrm{nmol} / \mathrm{LIF}$, washed twice with uptake buffer (in mmol/l) $\left(140 \mathrm{NaCl}, 20 \mathrm{HEPES}, 5 \mathrm{KCl}, 2.5 \mathrm{MgSO}_{4}\right.$, and $\left.1 \mathrm{CaCl}_{2}\right)$ and then incubated with the same buffer supplemented with 2- $\left[{ }^{3} \mathrm{H}(\mathrm{G})\right] \mathrm{deoxy}-\mathrm{D}$-glucose (American Radiolabeled Chemicals (ARC), Inc., MO, USA) $(37 \mathrm{kBq} /$ $\mathrm{ml})$ for $15 \mathrm{~min}$. The acute effect of LIF $(1 \mathrm{nmol} / \mathrm{l})$ on glucose uptake was assessed in cells exposed to LIF only during the 15 min glucose uptake period. Glucose uptake was performed with or without the presence of the mitogen-activated ERKactivating kinase (MEK) 1 inhibitor PD98059 (75 $\mu \mathrm{mol} / \mathrm{l}$; Calbiochem, La Jolla, CA, USA) or the PI3-kinase inhibitor wortmannin $(0.5 \mu \mathrm{mol} / 1$, Sigma). These inhibitors were added to the cells $60 \mathrm{~min}$ before measurement of deoxyglucose transport and were also present during the uptake period. In each experiment, a set of control cells was stimulated with $1 \mu \mathrm{mol} / 1$ insulin (Actrapid; Novo-Nordisk, Bagsvaerd, Denmark). Transport of labelled deoxyglucose was measured by liquid scintillation. Non-carrier-mediated transport was determined in the presence of $10 \mu \mathrm{mol} / 1$ cytochalasin B (Sigma) and subtracted from all presented values.

\section{Glucose oxidation}

Isolated cardiomyocytes were plated on $12.5 \mathrm{~cm}^{2}$ flasks (Falcon; Becton Dickinson, Franklin Lakes, NJ, USA) coated with laminin and maintained in culture for $48 \mathrm{~h}$. The control and LIF ( $1 \mathrm{nmol} / \mathrm{l})$-treated cells were then incubated with $\mathrm{D}-\left[1-{ }^{14} \mathrm{C}\right]$ glucose $(\mathrm{ARC})(7.4 \mathrm{kBq} / \mathrm{ml})$ and $20 \mathrm{mmol} / \mathrm{l}$ HEPES. Measurements of glucose oxidation followed procedures described elsewhere [5]. Flasks containing no cells were used to correct for non-specific $\mathrm{CO}_{2}$ trapping.

\section{Lipid metabolism}

\section{Oleic acid uptake, distribution and oxidation}

Measurement of lipid metabolism was performed in cells maintained in culture for $48 \mathrm{~h}$ followed by $4 \mathrm{~h}$ incubation with $\left[1-{ }^{14} \mathrm{C}\right]$ oleic acid (ARC) $(18.5 \mathrm{kBq} / \mathrm{ml})$ as previously described [5]. The distribution of oleic acid was determined 
by liquid scintillation counting after separation of labelledcell-associated lipids by thin layer chromatography. $\beta$ Oxidation of ${ }^{14} \mathrm{C}$-oleic acid was measured as acid soluble metabolites (ASMs). Complete oxidation of oleic acid to $\mathrm{CO}_{2}$ was measured in cardiomyocytes plated on $12.5 \mathrm{~cm}^{2}$ culture flasks (Falcon). No-cell controls were included. Total oleic acid uptake was calculated as the sum of ASM, the sum of lipids and oxidation to $\mathrm{CO}_{2}$.

Immunoblotting

Aliquots with $15 \mu \mathrm{g}$ cell protein (total cell lysate prepared in Laemmli buffer) were separated by SDS-PAGE $(10 \%$ resolving gel) and transferred to nitrocellulose membranes. The membranes were immunoblotted with antibodies against phosphorylated Akt/PKB (Ser473), phosphorylated extracellular signal regulated kinase (ERK)1, ERK2 (p40 mapk/ p42 ${ }^{\text {mapk }}$ ) (Thr202 plus Tyr204), phosphorylated AMPkinase $\alpha 1 / 2$ (Thr172) or phosphorylated glycogen synthase kinase (GSK)-3 $\alpha / \beta$ (Ser21/9) (all from Cell Signaling, Beverly, MA, USA). Immunoreactive bands were visualised with enhanced chemiluminescence (Amersham Biosciences, Bucks, UK). Quantification of western blots was performed with Gel-Pro Analyzer (ver. 2.0) software.

\section{Real-time quantitative RT-PCR}

Total RNA was isolated from cardiomyocytes using an Agilent Total RNA Isolation Kit (Matrix). Glyceraldehyde 3-phosphate dehydrogenase primer sequences were obtained from the RT primer database, entry 192 [17]. Other primers were designed using Primer Express TM Version 2.0 (Applied Biosystems, Foster City, CA, USA) (Table 1). RNA $(0.5 \mu \mathrm{g})$ was used to prepare cDNA using TaqMan Reverse Transcription Reagents (Applied Biosystems).
Quantification of mRNA was performed using the ABI PRISM 7000 (Applied Biosystems). Assays were performed in triplicates using Sybr Green Master Mix (Applied Biosystems) $30 \mu \mathrm{mol} / 1$ sense and anti-sense primers. Specificity of the assays was confirmed by gel electrophoresis. Gene expression was normalised to glyceraldehyde 3phosphate dehydrogenase.

\section{Statistics}

Groups were compared by the Mann-Whitney rank sum test and Bonferroni corrected where appropriate. A $p$ value $<0.05$ was considered statistically significant. Data are presented as means \pm SEM.

\section{Results}

Effect of acute LIF treatment on deoxyglucose transport

In the present study we investigated whether acute LIF treatment increased deoxyglucose transport in cardiomyocytes kept in culture for $48 \mathrm{~h}$. Our results showed that in cardiomyocytes treated with LIF $(1 \mathrm{nmol} / \mathrm{l})$ for $15 \mathrm{~min}$ deoxyglucose transport increased by $35 \pm 8 \%(p<0.01)$ compared with control cells (Fig. 1). Acute stimulation with insulin $(1 \mu \mathrm{mol} / \mathrm{l})$ increased deoxyglucose transport by $46 \pm 12 \%(p<0.05)$. No significant difference was found when comparing deoxyglucose transport mediated by acute LIF or insulin treatment. Nor were we able to detect any additive effect when cells were treated with both LIF and insulin compared with control cells $(47 \pm 15 \%, p<0.01)$ (Fig. 1$)$. The measurements of basal glucose uptake were higher while the insulinmediated uptake was lower than previously reported [18], and may be explained by different experimental conditions.

Table 1 Sequence of primers used in real-time RT-PCR assays

\begin{tabular}{|c|c|c|c|}
\hline Target & Direction & Sequence & Acc No. \\
\hline Slc2al & - & CACACAGTTGCTCCACATATTGG & NM_138827 \\
\hline Slc2a4 & - & CTGAAGAGCTCGGCCACAA & $\mathrm{BC} 085757$ \\
\hline \multirow[t]{2}{*}{ Socs 3} & + & CTGCGCCTCAAGACCTTC & \multirow[t]{2}{*}{ NM_053565 } \\
\hline & - & ATCCGCTCTCCTGCAGCTT & \\
\hline$C d 36$ & - & ACCAGGCCCAGGAGCTTTA & NM_031561 \\
\hline \multirow[t]{2}{*}{ Gapdh } & + & ATGATTCTACCCACGGCAAG & \multirow[t]{2}{*}{-} \\
\hline & - & CTGGAAGATGGTGATGGGTT & \\
\hline
\end{tabular}

+ forward primers; - reverse primers; Acc No. GenBank accession number; Slc2al, solute carrier family 2 (facilitated glucose transporter), member 1 (previously known as glucose transporter 1 [GLUT1]); Slc2a4, solute carrier family 2 (facilitated glucose transporter), member 4 (previously known as glucose transporter 4 [GLUT4]); Socs, suppressor of cytokine signalling; Cd36, fatty acid transporter Cd36 antigen; Gapdh, glyceraldehyde 3-phosphate dehydrogenase 


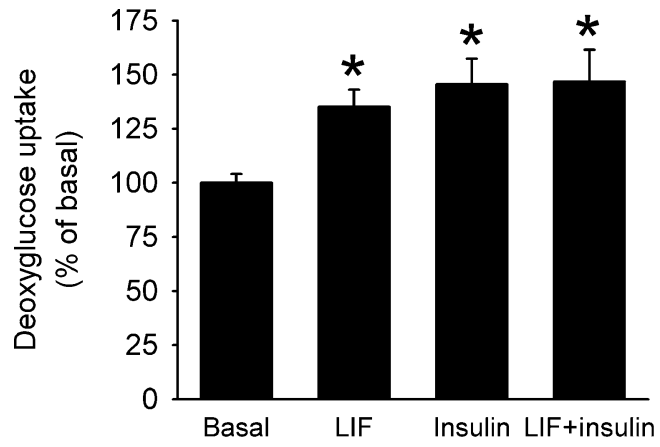

Fig. 1 Glucose transport in cardiomyocytes following acute exposure to LIF or insulin. Cardiomyocytes were kept in culture for $48 \mathrm{~h}$ before glucose transport was measured at the basal state and after stimulation with LIF $(1 \mathrm{nmol} / \mathrm{l})(n=5)$, insulin $(1 \mu \mathrm{mol} / \mathrm{l})(n=5)$ or the combination of these $(n=4)$ for $15 \mathrm{~min}$. Basal glucose uptake was $5.1 \pm 0.4 \mathrm{pmol} \cdot \mathrm{mg}^{-1} \cdot \mathrm{min}^{-1}$. Glucose transport is given as percentage of average basal uptake \pm SEM. ${ }^{*} p<0.05$ vs basal

Mechanism of the acute effect of LIF on deoxyglucose transport

To the best of our knowledge, it has not previously been reported that LIF has an acute effect on glucose uptake in cardiomyocytes. The mechanism by which LIF increases glucose uptake is therefore not known. We found that LIFstimulated glucose transport was not inhibited by wortmannin $(0.5 \mu \mathrm{mol} / \mathrm{l})$ (Fig. 2). However, wortmannin did inhibit insulin-induced glucose uptake. We also preincubated cells with the MEK1 inhibitor PD98059 (75 $\mu \mathrm{mol} / \mathrm{l})$ [19], which did not inhibit LIF-mediated deoxyglucose uptake (data not shown).

By immunoblotting experiments, we showed that the inhibitors wortmannin and PD98059 prevented LIF-induced phosphorylation of Akt/PKB and ERK1/2, respectively (Fig. 3a). In accord with the measurements of deoxyglucose transport, we observed no additive effect on phosphorylation of Akt/PKB or ERK1/2 in cells treated

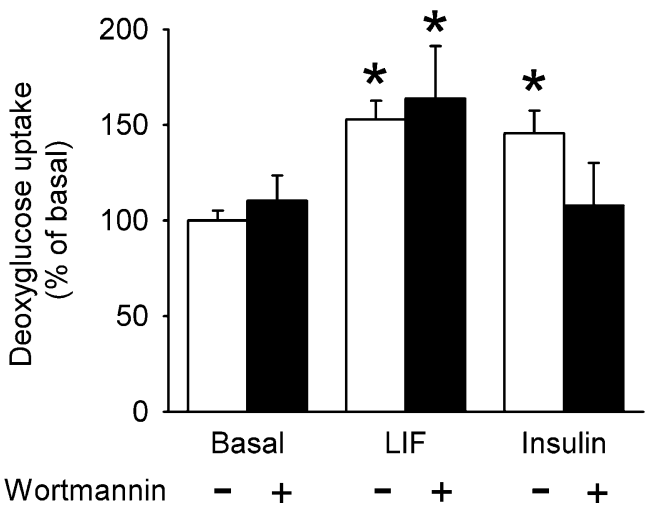

Fig. 2 Effect of wortmannin on acute LIF-stimulated glucose transport. Cardiomyocytes were kept in culture for $48 \mathrm{~h}$ before glucose uptake was measured for $15 \mathrm{~min}$ in the basal state and after stimulation with LIF $(1 \mathrm{nmol} / \mathrm{l})$ or insulin $(1 \mu \mathrm{mol} / \mathrm{l})$. Wortmannin $(0.5 \mu \mathrm{mol} / 1)$ was added to the cells $60 \mathrm{~min}$ prior to measurements of glucose transport. Basal glucose transport was $5.6 \pm 0.5$ pmol$\mathrm{mg}^{-1} \cdot \mathrm{min}^{-1}$. Glucose transport is given as percentage of basal uptake without wortmannin, means \pm SEM, $n=5$. ${ }^{*} p<0.05$ vs basal with both LIF and insulin (Fig. 3b,c). LIF did not alter the phosphorylation levels of AMPK (data not shown).

Effect of chronic LIF treatment on insulin-stimulated deoxyglucose transport

In accord with previous observations [5, 6], basal glucose uptake in the present study was increased by $20 \pm 4 \%$ after exposure to LIF ( $1 \mathrm{nmol} / \mathrm{l})$ for $48 \mathrm{~h}$ (Fig. 4). Interestingly, chronic LIF treatment induced a state of insulin resistance in the cardiomyocytes. Acute insulin stimulation increased deoxyglucose transport by $30 \pm 4 \%$ in control cells maintained in culture for $48 \mathrm{~h}$, whereas the insulin response was totally absent following chronic LIF treatment. We then examined whether treatment with insulin induced changes in glucose oxidation to $\mathrm{CO}_{2}$ in cells exposed to LIF for $48 \mathrm{~h}$. Insulin had
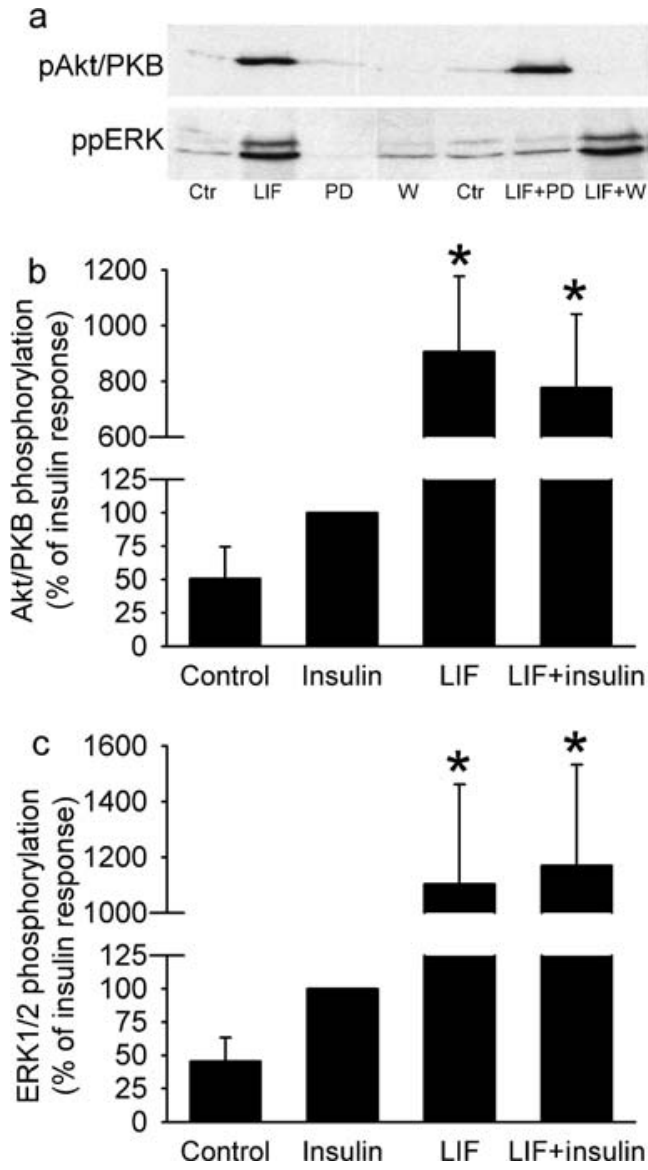

Fig. 3 Effect of acute LIF and insulin on phosphorylation of Akt/ $\mathrm{PKB}$ and ERK1/2. Cardiomyocytes were kept in culture for $48 \mathrm{~h}$ before stimulation with $\operatorname{LIF}(1 \mathrm{nmol} / \mathrm{l})$, insulin $(1 \mu \mathrm{mol} / \mathrm{l})$ or both LIF and insulin for $15 \mathrm{~min}$. One representative experiment is shown (a). Ctr, control; $\mathrm{p}$ and $\mathrm{pp}$, phosphorylated. Cell cultures were preincubated with wortmannin (W) $(0.5 \mu \mathrm{mol} / \mathrm{l})$ or PD98059 (PD) (75 $\mu \mathrm{mol} / \mathrm{l}$ ) for $60 \mathrm{~min}$ before LIF or insulin was added. Immunoblot analyses were performed using antibodies against phosphorylated Akt/PKB and phosphorylated ERK1/2. Densitometric analysis of results for Akt/PKB (b) and ERK 1/2 (c) are from five and six immunoblots, respectively, and presented as percentage of LIF response, means \pm SEM. ${ }^{*} p<0.05$ vs control 


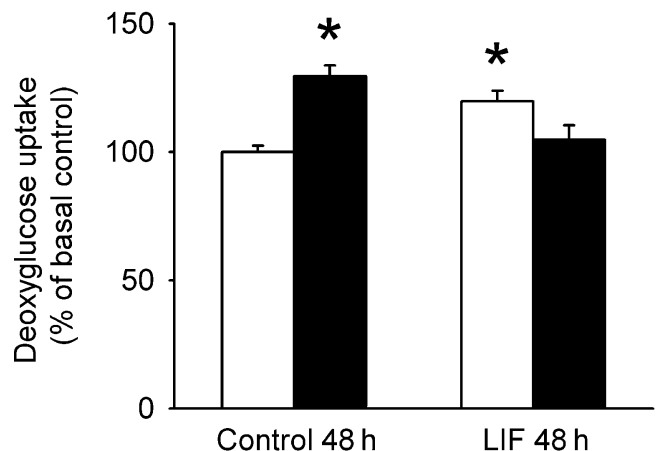

Fig. 4 Glucose transport after chronic exposure to LIF. Cardiomyocytes were incubated with LIF $(1 \mathrm{nmol} / \mathrm{l})$ for $48 \mathrm{~h}$ before basal (open bars) and insulin-stimulated $(1 \mu \mathrm{mol} / \mathrm{l})$ (closed bars) glucose transport was measured. Basal glucose transport in control cells was $5.4 \pm 0.4 \mathrm{pmol} \cdot \mathrm{mg}^{-1} \cdot \mathrm{min}^{-1}$. Results are presented as percentage of basal control, means \pm SEM from $6-9$ experiments. ${ }^{*} p<0.05$ vs basal uptake in control cells

no effect on control cells, nor did we detect changes between control and LIF-treated cells (data not shown).

We next examined whether chronic LIF treatment influenced the ability of insulin to phosphorylate intracellular signalling molecules. Insulin phosphorylated Akt/PKB in control cells maintained in culture for $48 \mathrm{~h}$ as expected. However, insulin did not significantly increase Akt/PKB phosphorylation in LIF-treated cardiomyocytes compared with control cells (Fig. 5a). We also observed that chronic LIF treatment prevented insulin-induced GSK-3 phosphorylation (Fig. 5b). Chronic LIF treatment did not alter the insulinmediated phosphorylation of ERK1/2 (data not shown).

Effect of chronic LIF treatment on insulin-stimulated fatty acid metabolism

Insulin has previously been shown to increase fatty acid uptake in cardiomyocytes [20]. Since we observed

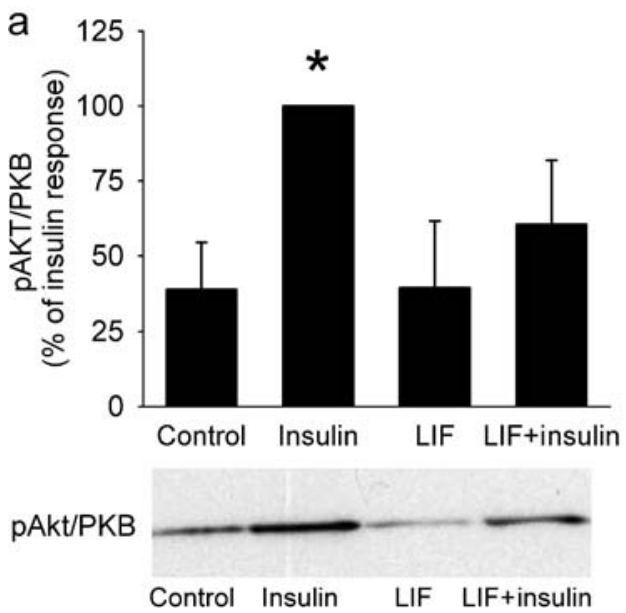

Fig. 5 Effect of chronic LIF treatment on insulin-stimulated phosphorylation of Akt/PKB (a) and GSK-3 (b). Cardiomyocytes were kept in culture for $48 \mathrm{~h}$ with or without the presence of LIF $(1 \mathrm{nmol} / \mathrm{l})$. Insulin $(1 \mu \mathrm{mol} / \mathrm{l})$ was added for the last $15 \mathrm{~min}$. One representative blot for each experiment is shown. Densitometric reduced glucose uptake by insulin in cardiomyocytes subjected to chronic LIF treatment, we examined the insulin-mediated uptake of fatty acids in these cells. Total oleic acid uptake in control cells was $148.4 \pm 14.3 \mathrm{nmol} / \mathrm{mg}$ protein (Fig. 6). Acute insulin stimulation increased oleic acid uptake by $29 \pm 1 \%(p<0.05)$, which is in agreement with a recent report [20]. Total uptake of oleic acid in cells exposed to LIF was $161.6 \pm 19.4 \mathrm{nmol} / \mathrm{mg}$ protein, and a $13 \pm 3 \%(p<0.01)$ increase was found following stimulation with insulin. The insulin-mediated increase in oleic acid uptake was lower in LIF-treated cells compared with controls $(59 \pm 9 \%, p<0.05)$. We also found that the intracellular distribution of oleic acid to diacylglycerol (DAG) and triacylglycerol (TAG) was lower in LIFtreated cells following insulin stimulation $(59 \pm 5$ and $46 \pm$ $4 \%$, respectively, of control values, $p<0.05$ ). Furthermore, insulin did not alter the intracellular level of free oleic acid, distribution of oleic acid to phospholipids or oleic acid oxidation (assessed as ASM and $\mathrm{CO}_{2}$ ).

LIF alters expression of genes involved in glucose metabolism

In order to understand the effects of chronic LIF treatment, we analysed gene expression of proteins involved in glucose and lipid metabolism. Our results showed that gene expression of suppressor of cytokine signalling (Socs) 3 was increased by $41 \pm 12 \%(p<0.05)$ in cells treated with LIF for $48 \mathrm{~h}$ (Fig. 7). Solute carrier family 2, member 1 (Slc2a1, previously known as glucose transporter 1 [GLUT1]) gene expression was increased by $39 \pm 10 \%$ $(p<0.05)$, while expression of Slc2a4 was reduced to $53 \pm$ $7 \%(p<0.05)$ of control. LIF did not change the expression of the fatty acid transporter $\mathrm{Cd} 36$.

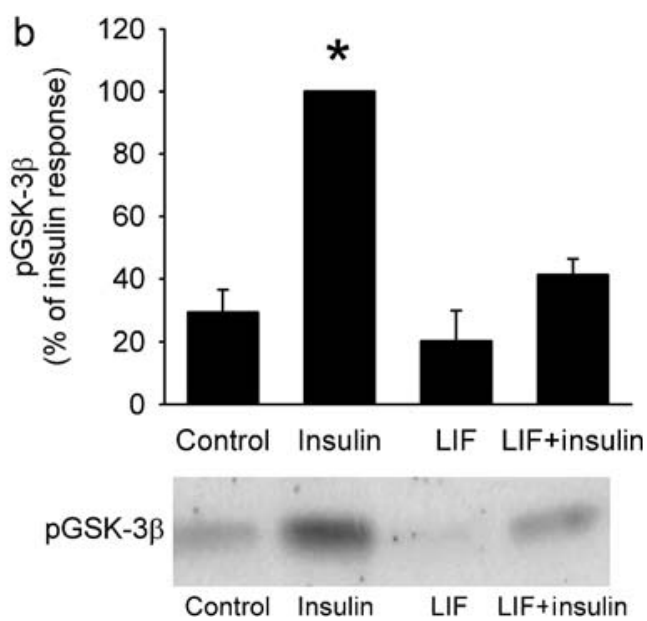

analysis of five (a) and three (b) immunoblots with antibody against phosphorylated Akt/PKB (pAkt/PKB) (a) and GSK-3 (pGSK-3 $\beta$ ) (b). Data presented as percentage of insulin response, means $\pm \mathrm{SEM}$. $* p<0.05$ vs control cells 


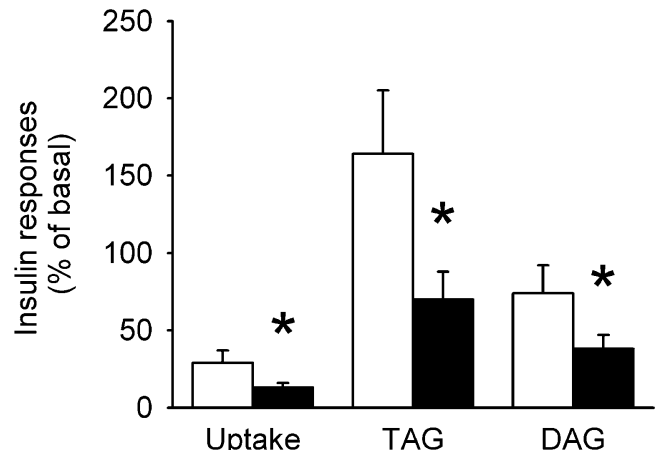

Fig. 6 Effects of insulin on $\left[{ }^{14} \mathrm{C}\right]$ oleic acid metabolism in cells exposed to LIF for $48 \mathrm{~h}$. Cells were treated with LIF $(1 \mathrm{nmol} / \mathrm{l})$ (filled bars) for $48 \mathrm{~h}$ (untreated cells used as control, open bars) and then incubated with $\left[{ }^{14} \mathrm{C}\right]$ oleic acid with or without insulin $(1 \mu \mathrm{mol} / \mathrm{l})$ for $4 \mathrm{~h}$. Insulin-mediated changes are calculated as the difference between values obtained when using insulin $(1 \mu \mathrm{mol} / \mathrm{l})$ and no insulin. Values are presented as means \pm SEM, $n=4-5$, ${ }^{*} p<0.05$

\section{Discussion}

The aim of this study was to investigate effects of acute LIF treatment on glucose uptake in cardiomyocytes, and to detect potential signalling pathways involved. In addition, we investigated whether chronic LIF treatment influenced the cellular responsiveness to insulin. We show that acute LIF treatment increases glucose uptake in cardiomyocytes through mechanisms that differ from those of insulinstimulated glucose uptake. Our results also show that chronic exposure to LIF induces insulin resistance. This chronic effect of LIF may be mediated by reduced insulin signalling and transcriptional changes in genes encoding proteins involved in the regulation of glucose uptake.

We found that acute LIF treatment increased glucose uptake in cardiomyocytes. A similar effect was observed with insulin, but there was no additive effect on glucose uptake of LIF and insulin in combination. Interestingly, the uptake mediated by LIF was not significantly different from the uptake induced by insulin. To the best of our knowledge, this is the first time that effects of acute LIF treatment on glucose uptake in cardiomyocytes have been shown. Insulin increases glucose uptake through the PI3kinase pathway by phosphorylating Akt/PKB [7] or through the $\mathrm{CAP} / \mathrm{Cbl}$ pathway [21]. Our results showed that the PI3-kinase inhibitor wortmannin did not abolish the LIF-induced glucose uptake, but prevented LIFstimulated phosphorylation of Akt/PKB. These results suggest that, in contrast to insulin, LIF increases glucose uptake in cardiomyocytes by a PI3-kinase-independent pathway. However, it remains to be investigated whether LIF and insulin share other signalling mechanisms such as the $\mathrm{CAP} / \mathrm{Cbl}$ pathway [22] to increase glucose uptake.

Insulin-independent pathways also contribute to increase glucose uptake in cardiomyocytes. Activation of AMPK has been reported to increase glucose uptake following ischaemia in cardiomyocytes [23]. However, we found no effect on
AMPK phosphorylation, suggesting that the effects of LIF are independent of this pathway. Activation of mitogenactivated protein kinase pathways also contributes to increased glucose uptake. It was recently shown that sodium nitroprusside increased glucose uptake through activation of ERK1/2 [24]. Our results showed that the MEK 1 inhibitor PD98059 did not prevent the LIF-induced acute uptake of glucose, despite inhibition of ERK1/2 phosphorylation. Since inhibiting the PI3-kinase or ERK1/2 pathways did not abolish the LIF-induced glucose uptake, it remains to be detected which pathways are responsible for these acute effects of LIF.

A novel finding in this study is that chronic LIF treatment induces insulin resistance. This was demonstrated as reduced insulin-mediated glucose uptake in cardiomyocytes exposed to chronic LIF treatment. In addition, chronic LIF treatment reduced the effects of insulin on the uptake of oleic acid. This lower insulin-mediated uptake may contribute to the reduced distribution of oleic acid to DAG and TAG compared with control cells. A potential consequence of the insulin-mediated increase in fatty acid uptake is a build-up of intracellular lipid stores in the cardiomyocytes [20]. Our result suggests, however, that chronic LIF treatment could prevent an accumulation of lipid stores following exposure to insulin by reducing the uptake of fatty acids. Thus, we believe that the reduced responses to insulin are important effects of chronic LIF treatment that may have functional consequences in the cardiomyocytes.

We show two possible mechanisms for the reduced insulin-mediated signalling following chronic exposure to LIF. Firstly, cardiomyocytes treated with LIF increased gene expression of Socs3. SOCS proteins modulate cytokine signalling in a negative feedback loop [25]. In addition, SOCS3 directly interacts with residues on the insulin receptor, inhibits tyrosine phosphorylation of insulin recep-

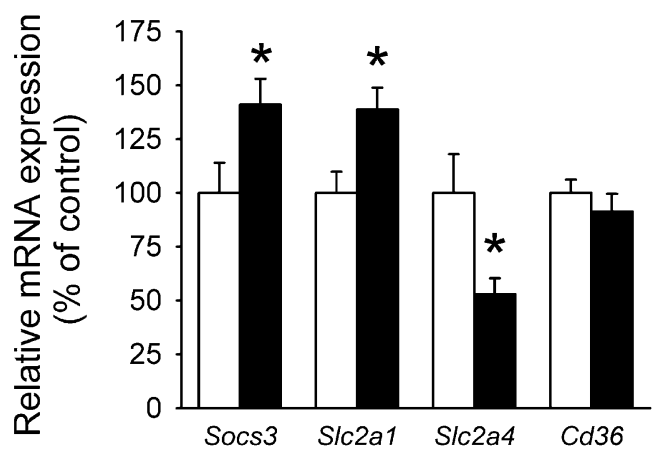

Fig. 7 Effects of LIF on gene expression. Gene expression was analysed in cells treated with LIF (1 nmol/1) (filled bars) for $48 \mathrm{~h}$ and control cells (untreated) (open bars). The levels of gene expression are normalised to the gene encoding glyceraldehyde 3-phosphate dehydrogenase (Gapdh). Values are normalised to control \pm SEM, $n=4,{ }^{*} p<0.05$ vs control. Socs 3 suppressor of cytokine signalling $3 ;$ Slc2al, solute carrier family 2 (facilitated glucose transporter), member 1 (previously known as glucose transporter 1 [GLUT1]); Slc2a1, solute carrier family 2 (facilitated glucose transporter), member 4 (previously known as glucose transporter 4 [GLUT4]); $C d 36$, fatty acid transporter $C D 36$ antigen 
tor substrate (IRS)-1 and impairs insulin signalling [26, 27]. Increased expression of the gene encoding SOCS3 following chronic LIF treatment may therefore contribute to the reduced insulin-mediated phosphorylation of $\mathrm{Akt} / \mathrm{PKB}$. The second negative effect of LIF on insulin signalling is potentially caused by regulating IRS-1 serine phosphorylation. Our results show that chronic LIF treatment impaired the ability of insulin to phosphorylate and thereby inactivate GSK-3. Active GSK-3 has been shown to serine phosphorylate IRS-1 and impair insulin-mediated signalling [28, 29]. Preventing insulin from phosphorylating GSK-3 may also explain why cardiomyocytes exposed to LIF for $48 \mathrm{~h}$ have reduced insulin-mediated signalling.

Reduced expression of the gene encoding the insulinsensitive glucose transporter SLC2A4 following chronic LIF treatment could also contribute to the induction of insulin resistance in these cardiomyocytes. A recent study found that reduced SLC2A4 translocation to the plasma membrane was partially responsible for induction of insulin resistance in isolated cardiomyocytes [8]. Thus, fewer available SLC2A4 proteins may therefore participate in the development of reduced responsiveness to insulin in the LIF-treated cardiomyocytes. Whether LIF prevents translocation of SLC2A4 to the plasma membrane remains to be investigated. Insulin translocates the fatty acid transporter CD36 to the plasma membrane and thereby participates in increasing fatty acid uptake in cardiomyocytes [20]. Our results showed that LIF did not alter expression of the gene encoding CD36. Further studies are needed to investigate whether LIF alters translocation of CD36 to the plasma membrane or changes expression of other fatty acid transporters.

This study demonstrates that acute and chronic LIF treatment of cardiomyocytes increase glucose uptake. LIF induces cardiomyocyte hypertrophy $[13,14]$, a process often associated with increased expression of foetal genes [30]. The present study reveals that LIF is also able to induce changes that resemble a foetal cardiomyocyte energy pattern and insulin resistance as found in hypertrophic hearts [11, 31]. Thus, LIF may contribute to increase the basal levels of glucose uptake and reduce the responsiveness of hypertrophic hearts to insulin. A possible limitation in this study is the use of supraphysiological insulin concentrations.

We conclude that acute LIF treatment increases glucose uptake in cardiomyocytes through mechanisms different from those of insulin. Furthermore, chronic LIF treatment alters the acute effects of insulin on uptake of both glucose and fatty acids. LIF may in part induce insulin resistance by altering expression of the genes encoding SOCS3 and SLC2A4, and reduce insulin-mediated phosphorylation of GSK-3 and Akt/PKB.

Acknowledgements This study was supported by the Norwegian Council for Cardiovascular Disease, Anders Jahre's Fund for the Promotion of Science, Ullevaal University Hospital Fund and The Norwegian Diabetes Association. We thank M. Eriksen and C. Lund for animal care, and A. V. Finsen, B. U. Mohebi and P. Ruud for skilful technical assistance.

\section{References}

1. Huss JM, Kelly DP (2005) Mitochondrial energy metabolism in heart failure: a question of balance. J Clin Invest 115:547-555

2. Leong HS, Brownsey RW, Kulpa JE, Allard MF (2003) Glycolysis and pyruvate oxidation in cardiac hypertrophywhy so unbalanced? Comp Biochem Physiol A Mol Integr Physiol 135:499-513

3. Eiken HG, Øie E, Damås JK et al (2001) Myocardial gene expression of leukaemia inhibitory factor, interleukin-6 and glycoprotein 130 in end-stage human heart failure. Eur J Clin Invest 31:389-397

4. Wollert KC, Drexler H (2001) The role of interleukin-6 in the failing heart. Heart Fail Rev 6:95-103

5. Florholmen G, Aas V, Rustan AC et al (2004) Leukemia inhibitory factor reduces contractile function and induces alterations in energy metabolism in isolated cardiomyocytes. J Mol Cell Cardiol 37:1183-1193

6. Morissette MR, Howes AL, Zhang T, Brown JH (2003) Upregulation of GLUT1 expression is necessary for hypertrophy and survival of neonatal rat cardiomyocytes. J Mol Cell Cardiol 35:1217-1227

7. Zorzano A, Sevilla L, Camps M et al (1997) Regulation of glucose transport, and glucose transporters expression and trafficking in the heart: studies in cardiac myocytes. Am J Cardiol 80:65A-76A

8. Rosenblatt-Velin N, Lerch R, Papageorgiou I, Montessuit C (2004) Insulin resistance in adult cardiomyocytes undergoing dedifferentiation: role of GLUT4 expression and translocation. FASEB J 18:872-874

9. Shulman GI (2000) Cellular mechanisms of insulin resistance. J Clin Invest 106:171-176

10. Luiken JJ, Coort SL, Koonen DP, Bonen A, Glatz JF (2004) Signalling components involved in contraction-inducible substrate uptake into cardiac myocytes. Proc Nutr Soc 63:251-258

11. Paternostro G, Pagano D, Gnecchi-Ruscone T, Bonser RS, Camici PG (1999) Insulin resistance in patients with cardiac hypertrophy. Cardiovasc Res 42:246-253

12. Shah A, Shannon RP (2003) Insulin resistance in dilated cardiomyopathy. Rev Cardiovasc Med 4(Suppl 6):S50-S57

13. Wollert KC, Taga T, Saito $M$ et al (1996) Cardiotrophin-1 activates a distinct form of cardiac muscle cell hypertrophy. Assembly of sarcomeric units in series via gp130/leukemia inhibitory factor receptor-dependent pathways. J Biol Chem 271:9535-9545

14. Matsui H, Fujio Y, Kunisada K, Hirota H, Yamauchi-Takihara K (1996) Leukemia inhibitory factor induces a hypertrophic response mediated by gp130 in murine cardiac myocytes. Res Commun Mol Pathol Pharmacol 93:149-162

15. Holt E, Christensen G (1997) Transient $\mathrm{Ca}^{2+}$ overload alters $\mathrm{Ca}^{2+}$ handling in rat cardiomyocytes: effects on shortening and relaxation. Am J Physiol 273:H573-H582

16. Eckel J, van Echten G, Reinauer H (1985) Adult cardiac myocytes in primary culture: cell characteristics and insulinreceptor interaction. Am J Physiol 249:H212-H221

17. Pattyn F, Speleman F, De Paepe A, Vandesompele J (2003) RTPrimerDB: the real-time PCR primer and probe database. Nucleic Acids Res 31:122-123

18. Eckel J, Asskamp B, Reinauer H (1991) Induction of insulin resistance in primary cultured adult cardiac myocytes. Endocrinology 129:345-352

19. Dudley DT, Pang L, Decker SJ, Bridges AJ, Saltiel AR (1995) A synthetic inhibitor of the mitogen-activated protein kinase cascade. Proc Natl Acad Sci USA 92:7686-7689

20. Luiken JJ, Koonen DP, Willems J et al (2002) Insulin stimulates long-chain fatty acid utilization by rat cardiac myocytes through cellular redistribution of FAT/CD36. Diabetes 51:3113-3119 
21. Baumann CA, Ribon V, Kanzaki M et al (2000) CAP defines a second signalling pathway required for insulin-stimulated glucose transport. Nature 407:202-207

22. Saltiel AR, Kahn CR (2001) Insulin signalling and the regulation of glucose and lipid metabolism. Nature 414:799-806

23. Russell RR III, Bergeron R, Shulman GI, Young LH (1999) Translocation of myocardial GLUT-4 and increased glucose uptake through activation of AMPK by AICAR. Am J Physiol 277:H643-H649

24. Jensen J, Sharikabad MN, Østbye KM, Melien Ø, Brørs O (2003) Evidence that nitroprusside stimulates glucose uptake in isolated rat cardiomyocytes via mitogen-activated protein kinase. Arch Physiol Biochem 111:239-245

25. Heinrich PC, Behrmann I, Haan S, Hermanns HM, MullerNewen G, Schaper F (2003) Principles of interleukin (IL)-6type cytokine signalling and its regulation. Biochem J 374:1-20

26. Emanuelli B, Peraldi P, Filloux C, Sawka-Verhelle D, Hilton D, Van Obberghen E (2000) SOCS-3 is an insulin-induced negative regulator of insulin signaling. J Biol Chem 275: 15985-15991
27. Ueki K, Kondo T, Kahn CR (2004) Suppressor of cytokine signaling 1 (SOCS-1) and SOCS-3 cause insulin resistance through inhibition of tyrosine phosphorylation of insulin receptor substrate proteins by discrete mechanisms. Mol Cell Biol 24:5434-5446

28. Eldar-Finkelman H, Krebs EG (1997) Phosphorylation of insulin receptor substrate 1 by glycogen synthase kinase 3 impairs insulin action. Proc Natl Acad Sci USA 94:9660-9664

29. Gual P, Marchand-Brustel Y, Tanti JF (2005) Positive and negative regulation of insulin signaling through IRS-1 phosphorylation. Biochimie 87:99-109

30. Chien KR, Knowlton KU, Zhu H, Chien S (1991) Regulation of cardiac gene expression during myocardial growth and hypertrophy: molecular studies of an adaptive physiologic response. FASEB J 5:3037-3046

31. Paternostro G, Clarke K, Heath J, Seymour AM, Radda GK (1995) Decreased GLUT-4 mRNA content and insulin-sensitive deoxyglucose uptake show insulin resistance in the hypertensive rat heart. Cardiovasc Res 30:205-211 